\title{
Effects of land use on phosphorus loss in the hilly area of the Loess Plateau, China
}

\author{
Qinghua Meng • Bojie Fu • Xiaoping Tang • \\ Hongchang Ren
}

Received: 7 November 2006 / Accepted: 18 May 2007 / Published online: 31 July 2007

(C) Springer Science + Business Media B.V. 2007

\begin{abstract}
The hilly area of Loess Plateau has some of the highest soil erosion rates in the world, and serious soil erosion causes great losses of plant nutrients. As the most common land use in Loess Plateau, slope farmland contributed most of the erosion soils. This study was designed to examine the effects of land use and slope angle of farmland on phosphorus (P) loss in the hilly area of loess plateau. Farmland (FR), barrenland (BR), and four forest treantment (seabuckthorn+ poplar (SP), immature seabuckthorn (IS), mature seabuckthorn (MS), immature Chinese pine (ICP)) were the types of land use; 10, 15, 20, 25, 30 degrees were the slope angles of FR that were compared. The results showed a larger proportion of $P$ loss occurred in erosion soil fraction of FR, ICP, ICP, and the five slope treatments of FR; in SP, IS, and MS, P loss was primarily through runoff. FR produced more P loss than SP, IS, ICP, BR, and MS.
\end{abstract}

Q. Meng $\cdot$ X. Tang $\cdot$ H. Ren

Academy of Forest Inventory and Planning,

State Forestry Administration,

Beijing, 100714, China

B. $\mathrm{Fu}(\bowtie)$

State Key Lab. of Urban and Regional Ecology,

Research Center for Eco-Environmental Sciences,

Chinese Academy of Sciences,

P. O. Box 2871, Beijing, 100085, China

e-mail: bfu@mail.rcees.ac.cn
20 30 degrees may be the slope ranges for P loss of FR; FR in this ranges would loss more $\mathrm{P}$ with soil erosion. SP, IS, and MS were reasonable land uses for their less runoff, soil loss, and P loss. Farmlands over 15 degrees should be abandoned or reforested for it would produce more runoff, soil loss, and P loss.

Keywords Land use $\cdot$ Soil erosion $\cdot \mathrm{P}$ loss $\cdot$ Hilly area . Loess Plateau

\section{Introduction}

The Loess Plateau of China has the highest rates of soil erosion in the world, with rates of 5,00010,000 $\mathrm{mg} \mathrm{km} \mathrm{yr}^{-1}$ (Chen and Luk 1989; Jiang 1997; Wu and Yang 1998; Chen et al. 2001), and inappropriate land use is one of the main reasons for soil loss (Fu et al. 2006). As the most common land use in the loess plateau ( $\mathrm{Fu}$ and Gulinck 1994), farming on steep sloping land contributes most of the 1.6 billion tons of erosion soil delivered into the Yellow River each year (Tang and Chen 1991; Fu et al. 2000).

Serious soil erosion causes great losses of plant nutrients (Trimble and Crosson 2000). In China's Loess Plateau, the total amount of nitrogen $(\mathrm{N})$, phosphorus (P) and potassium (K) lost with soil erosion is 40 million tons/year (Liu et al. 2001), and 
nutrients equivalent to $2,250 \mathrm{~kg} / \mathrm{ha}$ fertilizer have been lost from sloping farmlands in the hilly area (Zhang and Lu 1996). This vast amount of nutrient loss not only reduces on-site productivity (Kronvang et al. 1993; Foy et al. 1996), but creates massive environmental problems downstream (Nelson and Ehni 1976; Myers et al. 1985; Wang et al. 1993). This paper focuses on the P losses that occur through serious soil erosion under different land-use practices on steep slopes ( $>15$ degrees).

Studies have showed that, rangeland, conservation tillage and crop residue management, riparian zones, and constructed wetland all can reduce the rate and amount of $P$ loss via runoff and erosion (Sharpley et al. 1996; Chambers et al. 2000; Uusi-Kamppa et al. 2000). In the Loess Plateau, for the purpose of controlling soil erosion and developing agriculture, most studies focus on the effect of single land use on soil erosion and nitrogen loss (Peng 1982; Lu et al. 1988; Zhang and Lu 1996). A few studies have studied the P losses in the Loess Plateau. Through analyzing the soil sampled in the rivers, Tang et al. (1987) found the enrichment ratio for phosphorus in erosion soils delivered to the Yellow River ranged from 0.99 to 4.47. Wang and Liu 1999 studied the effect of land slope on P losses in the field plots, and found that the amount of $\mathrm{P}$ losses have a exponential function relation with slope degrees. But few studies have compared P losses from various sources (i.e., different kinds of land use) under the same conditions. Successful development and implementation of strategies to decrease $\mathrm{P}$ losses requires detailed information about the risk of $\mathrm{P}$ losses under different land use practices under the same conditions (Withers et al. 2000; Meng et al. 2001).

In 2000, Chinese government began to carry out the Western Development Programme. Control of soil erosion in Loess Plateau is one important part of this programme. At present, the population density of the Loess Plateau is about 144 persons per square kilometer (Wu and Yang 1998), and the overwhelming majorities are farmers. Control of soil erosion centers on land management practices may affect the daily activities of millions of people. Information regarding nutrient losses via soil erosion from different land use systems can provide valuable insight into development of sustainable agricultural systems that optimize production and maintain high environmental quality (Thomas et al. 1992).
The present study was designed to address the general need for basic information on the effects of land uses on phosphorus loss and to address the specific need for information about the reasonable utilization of more steeply sloping land in the Loess plateau. So the objectives of this study were:

(1) To study the effects of land use on P loss;

(2) To study the effects of slope angle on P loss;

(3) Based on (1) and (2), to suggest sustainable land use in the hilly area of Loess Plateau.

\section{Materials and methods}

Site description

Seventeen field plots $(5 \times 20 \mathrm{~m})$ were established and located at the An'sai Soil and Water Conservation Station $\left(36^{\circ} 41^{\prime} \mathrm{N}, 110^{\circ} 58^{\prime} \mathrm{E}\right)$, An'sai County, Shaanxi Province (Fig. 1). All the plots were on a calcic Cambisol (FAO-UNESCO 1974), which is weakly resistant to erosion. To reduce the effects of position, all plots were established across the slope. They were oriented parallel to the slope and adjacent to each other. The borders of the plots were delineated by cement ridges to isolate plot runoff and erosion soil. A discharge ditch was created at the top of each plot to control runoff and erosion soils from the upper slope. At the base of each plot, two volumetrically calibrated tanks were arranged in series for runoff and erosion soil collection.

This station is one of the stations of the Chinese Ecosystem Research Network, and is located in the northern part of the Loess Plateau, and has a semiarid climate, but the steppe land vegetation has been replaced - primarily by crops and shrub land. Mean annual precipitation in this station is about $473.9 \mathrm{~mm}$ (1929-1980), with about 60\% falling between June and September (Fig. 2). The maximum annual recorded rainfall was $851.0 \mathrm{~mm}$, which fell in 1964, and the minimum was $296.6 \mathrm{~mm}$ (in 1974). The average annual potential evapotranspiration is 1,556 mm (Shaanxi Province Meteorology Bureau 1992). The average annual temperature is $8.8^{\circ} \mathrm{C}$, and the annual average numbers of frost-free days is 159 . The high hills and deep ravines are the result of erosion of the $180 \mathrm{~m}$ deep loess, and some loess is lost every year (Jones and Despain 1995). 
Fig. 1 Study area and configuration of study plots
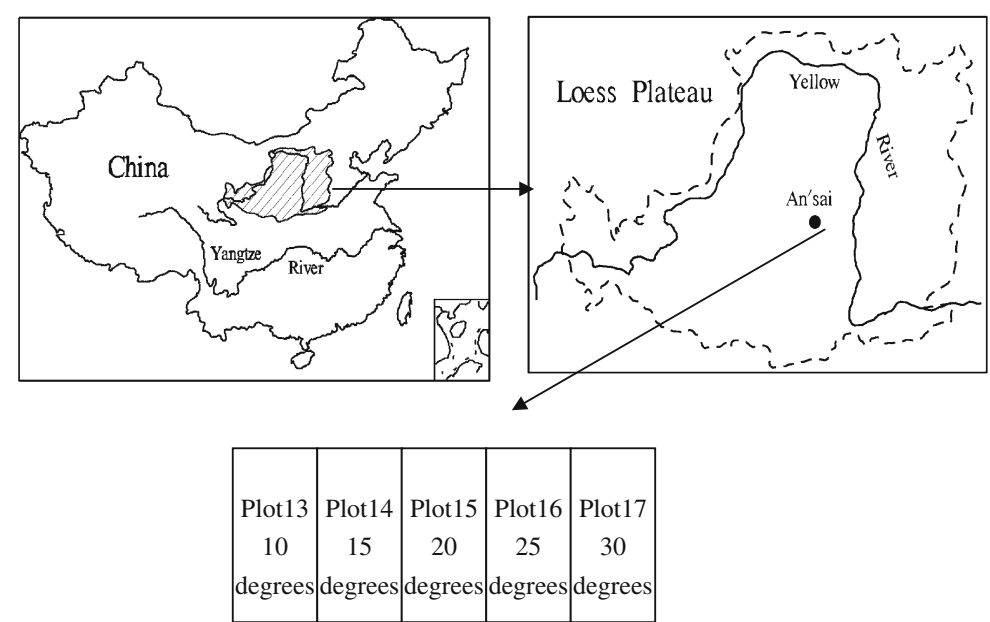

\begin{tabular}{|c|c|c|c|c|c|c|c|c|c|c|c|}
\hline Plot1 & Plot2 & Plot3 & Plot4 & Plot5 & Plot6 & Plot7 & Plot8 & Plot9 & Plot10 & Plot11 & Plot12 \\
SP & SP & IS & IS & FR & FR & BR & BR & ICP & ICP & MS & MS \\
\hline
\end{tabular}

upslope

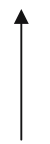

footslope

SP, seabuckthorn + poplar; IS, immature seabuckthorn; FR, Farmland; BR, barrenland; ICP, immature Chinese pine;

MS, mature seabuckthorn. The descriptions of plot see in text.

Treatment and management

Field plots represented six types of land use, and each use was replicated twice (Fig. 1). The land-use types included: sea buckthorn (Hippophae rhammoides)+ poplar (Populus simonii) (SP, plots 1 and 2); immature sea buckthorn (H. rhammoides) (IS, plots 3 and 4); farmland (FR, plots 5 and 6); barrenland (BR, plots 7 and 8); immature Chinese pine (Pinus tabulaeformis) (ICP, plots 9 and 10); mature sea buckthorn (H. rhammoides) (MS, plots 11 and 12). The 12 plots were established on a footslope and all had a uniform slope of 24 degrees. In 2001, the FR (plots 5 and 6) was fallowed to change farmland into grassland for the experiments.

Sloping farmland is the most common land use in the Loess Plateau, and it also produces most of the erosion soils delivered to the Yellow River. In order to test the effects of slope, five plots without replication (plots 13-17) were selected at the top of the same slope; they were used as FR (farmland) and sloped at 10, 15, 20, 25 and 30 degrees, respectively (Fig. 1).

The humus layers beneath SP, MS, and IS were thicker than that of the other land uses. Millet (Setaria italica) with contour tillage was planted on FR plots in the first ten days of May. Prior to planting, fertilizers (at $\mathrm{N}$ and $\mathrm{P}$ rates of 120 and $60 \mathrm{~kg} \mathrm{ha}^{-1}$ ) were applied to the FRs by harrowing.

\section{Methods}

Runoff and erosion soils were collected in two volumetrically calibrated tanks arranged in series at the base of each plot. The amount of water and erosion soils collected in each tank was measured after each erosive rainfall event.

Aliquot samples (one litre) of runoff in each tank were centrifuged at $2,500 \mathrm{rpm}$ for $30 \mathrm{~min}$ to separate erosion soils from the liquid. The supernatant liquid was retained after centrifugation and sent for $\mathrm{P}$

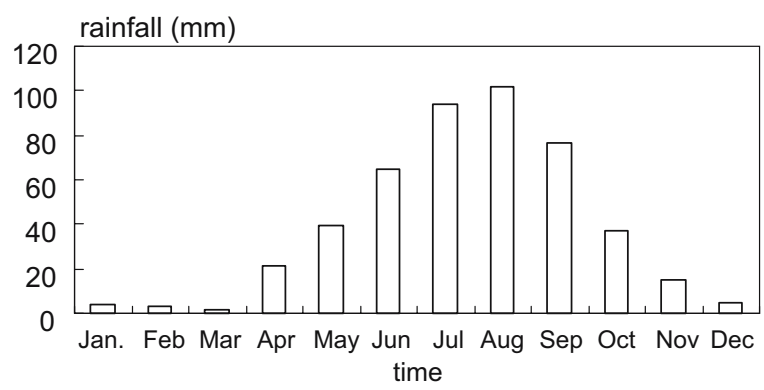

Fig. 2 Mean monthly precipitation in An'sai station (19291980) 
analysis within $24 \mathrm{~h}$, and the settled erosion soils were air-dried and weighed to calculate concentrations in grams. Water samples $(250 \mathrm{ml})$ of each erosive rainfall event, taken from the recording rain gauge, were also analyzed for P contents.

At the beginning and end of the study period, soil samples in each plot were collected, air-dried, and passed through 1.0 and $0.15 \mathrm{~mm}$ sieves. Its attached phosphorus content was determined calorimetrically after wet digestion with $\mathrm{H}_{2} \mathrm{SO}_{4}+\mathrm{HClO}_{4}$.

Water samples (including runoff and rainfall sample) were analyzed as follows: after digestion with $\mathrm{K}_{2} \mathrm{~S}_{2} \mathrm{O}_{8}$, dissolved $\mathrm{P}$ was determined calorimetrically.

Flow of runoff was expressed as:

Flow $(L)=$ Runoff depth $(\mathrm{cm})$

$$
\begin{aligned}
& \times \text { the square measure of } \operatorname{tank}\left(\mathrm{cm}^{2}\right) \\
& \times 10^{-3}
\end{aligned}
$$

P loss was expressed as the following equation:

$\mathrm{P}$ loss in runoff

$$
=\left[\text { Nutrient conc } .\left(\mathrm{mg} \mathrm{l}^{-1}\right) \times \text { Flow }(L)\right] \times \mathbf{N}
$$

P loss in erosion soils

$$
=\left[\text { Nutrient conc. }\left(\mathrm{g} \mathrm{kg}^{-1}\right) \times \operatorname{Weight}(\mathrm{kg})\right] \times \mathbf{N}
$$

Where $\mathbf{N}$ is the total number of erosive storms in each year.

\section{Results and discussion}

We have found that land uses have effects on runoff and erosion soil, and the observed data in this study period (Tables 1 and 2) could show the processes of soil erosion and $N$ loss from different land uses in this region (Fu et al. 2004). In this paper we will discuss the effects of land use on P loss.

Land use effects on changes of $\mathrm{P}$ content in runoff

$P$ concentrations in runoff of different land uses during the study periods (2000 and 2001) were listed in Table 3, and the correlation coefficient of $\mathrm{P}$ concentration with rainfall and intensity was showed in Fig. 3. the data showed that, as rainfall was the important factor triggering physical and chemical activities in semi-arid environment (Noy-Meir 1973), rainfall intensity had more effect on $\mathrm{P}$ concentration in runoff than the rainfall amount had in the six land uses (SP, IS, FR, BR, ICP, and MS) (Table 3 and Fig. 3). But for the first erosive storm in each year, $P$ concentration was higher relatively (Table 3 ). The reason was that strong rainfall intensity could make soil grains and runoff mixed adequately, and soil phosphorus exchanged fully between them. So $\mathrm{P}$ concentration in runoff was high.

In 2000, the average of $P$ content in runoff was in

\begin{tabular}{|c|c|c|c|c|c|c|c|c|c|c|c|c|}
\hline \multirow[t]{2}{*}{ Date } & \multirow[t]{2}{*}{ Rainfall (mm) } & \multicolumn{11}{|c|}{ Runoff for treatment (1) } \\
\hline & & SP & IS & FR & BR & ICP & MS & FR $10^{\circ}$ & FR $15^{\circ}$ & FR $20^{\circ}$ & FR $25^{\circ}$ & FR $30^{\circ}$ \\
\hline $9 / 7 / 00$ & 32.8 & 110.3 & 97.5 & 154.1 & 152.7 & 154.1 & 50.9 & 602.2 & 692.7 & 715.3 & 783.2 & 511.8 \\
\hline $15 / 7 / 00$ & 13.7 & 28.3 & 24 & 327 & 70.7 & 212.1 & 53.7 & 31.1 & 48.1 & 65 & 33.9 & 21.2 \\
\hline $27 / 7 / 00$ & 28 & 38.2 & 32.5 & 552.8 & 120.2 & 118.8 & 35.3 & 113.1 & 231.8 & 144.2 & 108.9 & 33.9 \\
\hline $8 / 8 / 00$ & 42 & 86.2 & 46.9 & 69.3 & 39.6 & 41 & 9.9 & 56.5 & 121.6 & 121 & 73.5 & 30.9 \\
\hline $13 / 8 / 00$ & 18.3 & 28.3 & 20.9 & 36.8 & 52.3 & 113.1 & 7.1 & 55.1 & 135.7 & 149.9 & 141.4 & 46.7 \\
\hline Total & 134.8 & 291.3 & 221.8 & 1,140 & 435.5 & 639.1 & 156.9 & 858 & $1,229.9$ & $1,195.4$ & $1,140.9$ & 644.5 \\
\hline $20 / 7 / 01$ & 27 & 38.2 & 31.1 & 12.4 & 11 & 4.9 & 0 & 0 & 0 & 0 & 0 & 0 \\
\hline $24 / 7 / 01$ & 5.7 & 15.7 & 21.6 & 41.7 & 50.9 & 64.6 & 3.5 & 0 & 0 & 0 & 0 & 0 \\
\hline $27 / 7 / 01$ & 45 & 93 & 58 & 75.4 & 131.5 & 120.9 & 3.5 & 79.2 & 73.5 & 53.7 & 49.5 & 25.4 \\
\hline $16 / 8 / 01$ & 22 & 117.3 & 119.5 & 47.4 & 60.8 & 125.8 & 8.9 & 21.2 & 18.2 & 17.7 & 16.4 & 14.4 \\
\hline $18 / 8 / 01$ & 40 & 111.8 & 150.1 & 38.7 & 50.9 & 86.5 & 15 & 149.9 & 85.4 & 110.8 & 89.6 & 147.6 \\
\hline Total & 139.7 & 376 & 380.3 & 215.6 & 305.1 & 402.7 & 30.9 & 250.3 & 177.1 & 182.2 & 155.5 & 187.4 \\
\hline
\end{tabular}
the order: $\mathrm{BR}>\mathrm{ICP}>\mathrm{MS}>\mathrm{SP}=\mathrm{IS}>\mathrm{FR}$. In 2001, the average of $P$ content in runoff was in the

Table 1 Runoff volume of each plot in the study periods (2000-2001)

$S P$ seabuckthorn+poplar, IS immature seabuckthorn, FR Farmland, BR barrenland, ICP immature Chinese pine, $M S$ mature seabuckthorn. 
Table 2 Soil loss from per plot in the study periods (2000-2001)

\begin{tabular}{|c|c|c|c|c|c|c|c|c|c|c|c|c|}
\hline \multirow[t]{2}{*}{ Date } & \multirow[t]{2}{*}{ Rainfall (mm) } & \multicolumn{11}{|c|}{ Soil loss for treatment $(\mathrm{kg})$} \\
\hline & & SP & IS & FR & $\mathrm{BR}$ & ICP & MS & FR $10^{\circ}$ & FR $15^{\circ}$ & FR $20^{\circ}$ & FR $25^{\circ}$ & FR $30^{\circ}$ \\
\hline $9 / 7 / 00$ & 32.8 & 0 & 0 & 41.3 & 4.7 & 18 & 0 & 45.3 & 67.3 & 117.1 & 136.7 & 123.3 \\
\hline $15 / 7 / 00$ & 13.7 & 0 & 0 & 39.4 & 0.8 & 25 & 0 & 1.8 & 3.8 & 9.1 & 5.1 & 6 \\
\hline $27 / 7 / 00$ & 28 & 0 & 0 & 156 & 10.7 & 3.3 & 0 & 2.8 & 10.3 & 8.6 & 7.2 & 1.2 \\
\hline $8 / 8 / 00$ & 42 & 0 & 0 & 2.3 & 0.3 & 0 & 0 & 1.3 & 1.8 & 2.9 & 2.5 & 0.6 \\
\hline $13 / 8 / 00$ & 18.3 & 0 & 0 & 1.2 & 0.4 & 0 & 0 & 1.3 & 1.7 & 0.7 & 0.6 & 0.2 \\
\hline Total & 134.8 & 0 & 0 & 240.3 & 16 & 46.2 & 0 & 52.4 & 85 & 138.5 & 152.2 & 130.7 \\
\hline $20 / 7 / 01$ & 27 & 0.0 & 0.0 & 0.0 & 0.0 & 0.0 & 0.0 & 0.0 & 0.0 & 0.0 & 0.0 & 0.0 \\
\hline $24 / 7 / 01$ & 5.7 & 0.1 & 0.1 & 0.5 & 0.2 & 0.6 & 0.0 & 0.0 & 0.0 & 0.0 & 0.0 & 0.0 \\
\hline $27 / 7 / 01$ & 45 & 0.6 & 0.0 & 0.7 & 0.0 & 0.0 & 0.0 & 0.6 & 1.2 & 0.5 & 0.9 & 0.0 \\
\hline $16 / 8 / 01$ & 22 & 0.6 & 0.5 & 0.0 & 0.0 & 0.4 & 0.0 & 0.3 & 0.1 & 0.1 & 0.1 & 0.2 \\
\hline $18 / 8 / 01$ & 40 & 0.6 & 0.5 & 0.0 & 0.0 & 0.4 & 0.0 & 3.9 & 1.7 & 1.6 & 0.8 & 4.5 \\
\hline Total & 139.7 & 1.9 & 1.1 & 1.2 & 0.3 & 1.4 & 0.0 & 4.8 & 3.0 & 2.3 & 1.8 & 4.6 \\
\hline
\end{tabular}

$S P$ seabuckthorn+poplar, IS immature seabuckthorn, $F R$ Farmland, $B R$ barrenland, ICP immature Chinese pine, $M S$ mature seabuckthorn.

order: $\mathrm{BR}>\mathrm{ICP}>\mathrm{FR}>\mathrm{SP}>\mathrm{IS}>\mathrm{MS}$. In 2000, although fertilizer was used in FR, $P$ concentration in runoff was less than that of SP, MS, and IS. In 2001, FR was fallowed, and no fertilizer was used, but $P$ concentration was higher than that of SP, MS, and IS. Various land coverage might be the reason. This result showed that different land use system had various capabilities to regulate $\mathrm{P}$ concentration in runoff. So in a landscape, rational spatial heterogeneity of different land use system could alter the $\mathrm{P}$ concentration in runoff at reasonable level.
For slope treatments of farmland, phosphorus concentration in runoff decreased with rainfall events, and rainfall intensity had more significant effect on $\mathrm{P}$ concentration than rainfall amount had (Table 3 and Fig. 4). From 10 to 30 degrees, phosphorus concentration in runoff first decreased, and then increased. Except for the phosphorus dynamics caused by slope degrees, different amount of runoff was one of the reasons (Table 1). There was little difference of the average of phosphorus concentration in runoff between 20 and 25 degrees (Table 3). This meant there

Table 3 Pconcentrations in runoff of different land uses by runoff event $(\mathrm{mg} / \mathrm{l})$

\begin{tabular}{|c|c|c|c|c|c|c|c|c|c|c|c|c|c|}
\hline Date & Rainfall (mm) & Intensity $(\mathrm{mm} / \mathrm{min})$ & SP & IS & FR & $\mathrm{BR}$ & ICP & MS & FR $10^{\circ}$ & FR $15^{\circ}$ & FR $20^{\circ}$ & $\mathrm{FR} 25^{\circ}$ & FR $30^{\circ}$ \\
\hline 9/7/00 & 32.8 & Thin & 0.07 & 0.22 & 0.19 & 0.40 & 0.30 & 0.04 & 0.57 & 0.24 & 0.13 & 0.14 & 0.80 \\
\hline $15 / 7 / 00$ & 13.7 & Strong & 0.19 & 0.13 & 0.17 & 0.08 & 0.18 & 0.18 & 0.56 & 0.33 & 0.48 & 0.61 & 0.48 \\
\hline $27 / 7 / 00$ & 28 & Very strong & 0.36 & 0.35 & 0.12 & 0.70 & 0.52 & 0.57 & 0.30 & 0.13 & 0.22 & 0.17 & 0.19 \\
\hline $8 / 8 / 00$ & 42 & Thin & 0.10 & 0.06 & 0.06 & 0.09 & 0.03 & 0.09 & 0.06 & 0.05 & 0.04 & 0.05 & 0.00 \\
\hline $13 / 8 / 00$ & 18.3 & Strong & 0.07 & 0.03 & 0.05 & 0.03 & 0.03 & 0.26 & 0.07 & 0.05 & 0.07 & 0.08 & 0.17 \\
\hline \multicolumn{3}{|c|}{ Average of $\mathrm{P}$ content in 2000} & 0.16 & 0.16 & 0.12 & 0.26 & 0.21 & 0.23 & 0.31 & 0.16 & 0.19 & 0.21 & 0.33 \\
\hline 20/7/01 & 27 & 0.05 & 0.15 & 0.16 & 0.26 & 0.27 & 0.23 & 0.00 & 0.00 & 0.00 & 0.00 & 0.00 & 0.00 \\
\hline $24 / 7 / 01$ & 5.7 & 0.11 & 0.12 & 0.05 & 0.13 & 0.15 & 0.10 & 0.00 & 0.00 & 0.00 & 0.00 & 0.00 & 0.00 \\
\hline $27 / 7 / 01$ & 45 & 0.05 & 0.09 & 0.08 & 0.06 & 0.07 & 0.06 & 0.00 & 0.27 & 0.15 & 0.14 & 0.15 & 0.00 \\
\hline $16 / 8 / 01$ & 22 & 0.14 & 0.11 & 0.08 & 0.06 & 0.08 & 0.17 & 0.30 & 0.33 & 0.30 & 0.28 & 0.29 & 0.49 \\
\hline $18 / 8 / 01$ & 40 & 0.02 & 0.05 & 0.08 & 0.06 & 0.07 & 0.04 & 0.10 & 0.17 & 0.25 & 0.25 & 0.21 & 0.57 \\
\hline \multicolumn{3}{|c|}{ Average of P content in 2001} & 0.10 & 0.09 & 0.11 & 0.13 & 0.12 & 0.08 & 0.15 & 0.14 & 0.13 & 0.13 & 0.21 \\
\hline
\end{tabular}

$S P$ seabuckthorn+poplar, IS immature seabuckthorn, FR Farmland, BR barrenland, ICP immature Chinese pine, $M S$ mature seabuckthorn. 


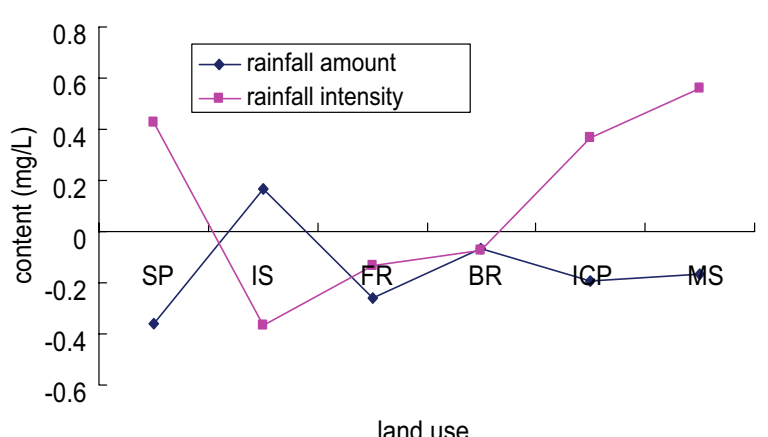

Fig. 3 Correlation coefficient of P loss in runoff with rainfall amount and intensity of the six land uses

might be a range of slope degree, not a single critical value, and when a slope exceeds the range, $P$ concentration in runoff would increase.

Some of the observed data of $\mathrm{P}$ concentration in runoff were over $0.1 \mathrm{mg} / \mathrm{l}$, even $0.8 \mathrm{mg} / 1$ (Table 3 ). This meant, in the hilly area of loess plateau, current level of soil phosphorus could cause eutrophication of downstream water (Sharpley et al. 2000). As the study site was in the subarea short of nitrogen and phosphorus (Jia et al. 1994), controlling runoff from FR was helpful to abate the phosphorus pollution press of downstream water of Yellow river.

Land use effects on changes of $\mathrm{P}$ content in erosion soil

Table 4 summarized the average of $\mathrm{P}$ content in erosion soil. Compared to Table 3, P content in erosion soil was much higher than that in runoff due to the highly adsorbed and immobile state of soil $\mathrm{P}$ forms (Gilliam et al. 1985), and this also indicated the importance of keeping soil for controlling P loss. For the enrichment process (Zhang and Shao 2000), erosion soils had more proportion of fine soil grains and higher $\mathrm{P}$ content, so differences of $\mathrm{P}$ content in erosion soil among land uses were little (Table 4). This result was similar with the findings of other researchers (Chen and Zhang 1990).

The average of $\mathrm{P}$ content in erosion soil of SP and IS was higher than that of FR, BR, and ICP, and no P loss in erosion soil from MS (Table 4). The humus layer of MS, SP and IS was one of the reasons (Thomas et al. 1992). Fertilization in FR had no effect on $\mathrm{P}$ content in erosion soil for the low value. This showed the various soil phosphorus dynamics in different land uses.
For slope treatments of farmland, FR of 10 degrees had higher $\mathrm{P}$ content in erosion soil than that in the other four slope treatments, and there were little differences of $\mathrm{P}$ content among 15, 20, 25, and 30 degrees FR. This meant slope degree had little effect on $\mathrm{P}$ content in erosion soil. Compared to the findings of Chen and Zhang (1990), P content in this study was higher. This showed crop residues may increase soil P content (Sharpley et al. 1991), and area may also enlarge the enrichment process of fine soil grains.

\section{Land use effects on P loss in runoff}

Phosphorus lost with runoff is a function of runoff volume and solute concentration. $\mathrm{P}$ losses in runoff from different land uses in the study period were listed in Table 5. It is clear that P loss in runoff was determined by runoff amount, not the $\mathrm{P}$ content (Tables 1 and 3). In 2001, as the first erosive storm occurred in July 20th, the overlay of every plot was thick and changed little, and runoff was less than that in the first ten days of July, so P loss in 2001 was much less than that in 2000 . This result meant that the first ten days of July had significant effect on P loss in runoff.

In 2000, P loss in runoff was in the order: $F R>I C P$ $>$ BR $>$ SP $>$ IS $>$ MS; in 2001, the order was: ICP $>$ SP $>$ $\mathrm{BR}>\mathrm{IS}>\mathrm{FR}>\mathrm{MS}$. The data showed, when FR was fallowed, $\mathrm{P}$ loss in runoff would decreased dramatically (Table 5). This meant FR was not reasonable land use type for its high P losses in runoff. The data also showed that the time difference of erosive storm occurred has little effect on P loss in runoff from SP

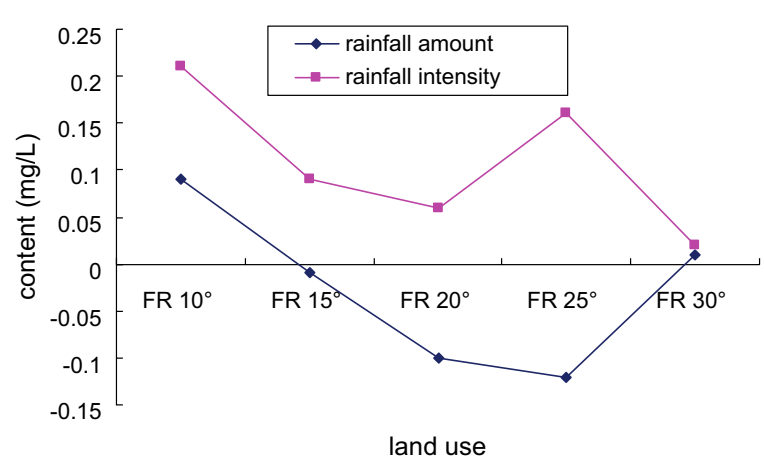

Fig. 4 Correlation coefficient of P loss in runoff with rainfall amount and intensity of the five slope treatment 
Table 4 Average of $\mathrm{P}$ content in erosion soil of different land uses (\%)

\begin{tabular}{|c|c|c|c|c|c|c|c|c|c|c|c|c|c|}
\hline & $\begin{array}{l}\text { Area } \\
\left(\mathrm{m}^{2}\right)\end{array}$ & Land cover & SP & IS & FR & BR & $\mathrm{ICP}$ & MS & FR $10^{\circ}$ & FR $15^{\circ}$ & FR $20^{\circ}$ & FR $25^{\circ}$ & FR $30^{\circ}$ \\
\hline This study & 100 & Crop overlay & 0.065 & 0.069 & 0.052 & 0.056 & 0.055 & - & 0.062 & 0.056 & 0.057 & 0.057 & 0.059 \\
\hline $\begin{array}{l}\text { Chen and Zhang } \\
1990\end{array}$ & 5 & $\begin{array}{l}\text { No crop } \\
\text { overlay }\end{array}$ & & & & & & & 0.044 & 0.041 & & 0.041 & \\
\hline
\end{tabular}

$S P$ seabuckthorn+poplar, IS immature seabuckthorn, FR Farmland, BR barrenland, ICP immature Chinese pine, $M S$ mature seabuckthorn.

and IS for the little changes of P loss between 2000 and 2001, and ICP had the highest P loss than the other five land use types from 2000 to 2001.

For the slope treatments of FR, as there were only three runoff events in 2001, and the amount of $\mathrm{P}$ losses was much less than that in 2000 (Table 5). So we combined the data of 2000 and 2001 together to discuss the slope effect on P losses (Table 5). From 10 to 30 degrees, $\mathrm{P}$ lost with runoff first decreased, and then increased. Twenty-five degrees was the turning point of slope. This meant 25 degrees was the critical value for $\mathrm{P}$ loss in runoff from FR, and slope land over 25 degrees was not used as FR. And we don't know why 10 degree FR would produce the highest $P$ loss in runoff. Combined Tables 1 and 3 together, although 15, 20, and 25 degrees FR produced more runoff volume, $\mathrm{P}$ losses of the three treatments were lower. This meant phosphorus concentration was the main factor for P loss of FR, not the runoff volume.
Land use effects on P Loss in erosion soil

Phosphorus lost with erosion soil was a function of erosion soil amount and $\mathrm{P}$ concentration. Table 6 showed P loss in erosion soil from the six land uses and the five slope treatments of FR. It was obvious that $\mathrm{P}$ lost with erosion soil was through one or two rainfall events (Table 6). When FR was fallowed in 2001, P loss in erosion soil decreased significantly. As $\mathrm{P}$ content in erosion soil changed little among land uses for the enrichment effect of fine soil grains (Table 4), the amount of erosion soil determined the mass of phosphorus loss.

FR produced much more $\mathrm{P}$ than ICP and BR did. The reason for this was attributed primarily to fertilization (Meng et al. 2001). More erosion soil from FR was another reason (Table 2). There were no $\mathrm{P}$ losses of SP, IS, and MS because of the better soil structure and thick coverage. This meant keeping

Table $5 \mathrm{P}$ loss in runoff of different land uses by runoff event (mg)

\begin{tabular}{|c|c|c|c|c|c|c|c|c|c|c|c|}
\hline Date & SP & IS & FR & $\mathrm{BR}$ & ICP & MS & FR $10^{\circ}$ & FR $15^{\circ}$ & FR $20^{\circ}$ & FR $25^{\circ}$ & FR $30^{\circ}$ \\
\hline 9/7/00 & 7.9 & 21.4 & 29.8 & 60.5 & 46.5 & 1.9 & 391.4 & 168.1 & 101.0 & 70.1 & 312.3 \\
\hline $15 / 7 / 00$ & 5.5 & 3.0 & 55.1 & 5.5 & 38.9 & 9.7 & 27.0 & 21.7 & 16.3 & 12.9 & 13.0 \\
\hline $27 / 7 / 00$ & 13.8 & 11.3 & 63.8 & 83.5 & 62.0 & 20.1 & 68.6 & 18.6 & 24.0 & 5.7 & 12.9 \\
\hline $8 / 8 / 00$ & 8.2 & 2.8 & 4.2 & 3.4 & 1.3 & 0.8 & 6.9 & 5.9 & 2.9 & 1.5 & 0.0 \\
\hline $13 / 8 / 00$ & 2.1 & 0.6 & 2.0 & 1.5 & 3.4 & 1.8 & 8.8 & 7.9 & 10.3 & 3.6 & 1.5 \\
\hline Total of 2000 & 37.5 & 39.1 & 154.9 & 154.4 & 152.1 & 34.3 & 502.7 & 222.2 & 154.5 & 93.8 & 339.7 \\
\hline $20 / 7 / 01$ & 5.8 & 4.8 & 3.2 & 2.9 & 1.1 & 0.0 & 0.0 & 0.0 & 0.0 & 0.0 & 0.0 \\
\hline $24 / 7 / 01$ & 1.9 & 1.2 & 5.4 & 7.7 & 6.4 & 0.0 & 0.0 & 0.0 & 0.0 & 0.0 & 0.0 \\
\hline $27 / 7 / 01$ & 8.3 & 4.9 & 4.2 & 9.3 & 7.8 & 0.0 & 19.8 & 8.2 & 7.1 & 3.9 & 0.0 \\
\hline $16 / 8 / 01$ & 12.7 & 10.1 & 3.0 & 4.8 & 21.9 & 2.6 & 6.0 & 5.3 & 4.6 & 4.2 & 2.9 \\
\hline $18 / 8 / 01$ & 5.9 & 11.6 & 2.4 & 3.7 & 3.5 & 1.5 & 14.4 & 27.5 & 22.2 & 30.6 & 8.2 \\
\hline Total of 2001 & 34.6 & 32.6 & 18.2 & 28.4 & 40.7 & 4.1 & 40.2 & 41 & 33.9 & 38.7 & 11.1 \\
\hline Total of 2000 and 2001 & 72.1 & 71.7 & 173.1 & 182.8 & 192.8 & 38.4 & 542.9 & 263.2 & 188.4 & 132.5 & 350.8 \\
\hline
\end{tabular}

$S P$ seabuckthorn+poplar, IS immature seabuckthorn, FR Farmland, BR barrenland, ICP immature Chinese pine, $M S$ mature seabuckthorn. 
Table 6 P loss in erosion soil of different land uses by runoff event $(\mathrm{g})$

\begin{tabular}{lrrrrrrrrrrr}
\hline Date & SP & IS & FR & BR & ICP & MS & FR 10 & FR 15 & FR 20 & FR 25 & FR 30 \\
\hline $9 / 7 / 00$ & 0 & 0 & 1,982 & 237 & 963 & 0 & 2,718 & 3,567 & 5,855 & 7,108 & 6,288 \\
$15 / 7 / 00$ & 0 & 0 & 1,950 & 38 & 1,400 & 0 & 115 & 209 & 501 & 296 & 378 \\
$27 / 7 / 00$ & 0 & 0 & 8,736 & 578 & 175 & 0 & 157 & 608 & 499 & 403 & 67 \\
$8 / 8 / 00$ & 0 & 0 & 104 & 14 & 0 & 0 & 78 & 108 & 174 & 150 & 36 \\
$13 / 8 / 00$ & 0 & 0 & 54 & 18 & 0 & 0 & 78 & 102 & 42 & 36 & 12 \\
Total of 2000 & 0 & 0 & 12,826 & 885 & 2,538 & 0 & 3,146 & 4,594 & 7,071 & 7,993 & 6,781 \\
$20 / 7 / 01$ & 0 & 0 & 0 & 0 & 0 & 0 & 0 & 0 & 0 & 0 \\
$24 / 7 / 01$ & 8 & 8 & 33 & 14 & 33 & 0 & 0 & 0 & 0 & 0 \\
$27 / 7 / 01$ & 48 & 0 & 46 & 0 & 0 & 0 & 41 & 70 & 32 & 57 \\
$16 / 8 / 01$ & 48 & 40 & 0 & 0 & 22 & 0 & 20 & 6 & 6 & 6 \\
$18 / 8 / 01$ & 43 & 38 & 0 & 0 & 20 & 0 & 265 & 99 & 102 & 50 \\
Total of 2001 & 147 & 86 & 79 & 14 & 75 & 0 & 326 & 175 & 140 & 113 \\
Total of 2000 and 2001 & 147 & 86 & 12,905 & 899 & 2,613 & 0 & 3,472 & 4,769 & 7,211 & 8,106 & 7,063 \\
\hline
\end{tabular}

$S P$ seabuckthorn+poplar, IS immature seabuckthorn, $F R$ Farmland, $B R$ barrenland, ICP immature Chinese pine, $M S$ mature seabuckthorn.

good soil structure and thick land cover was helpful to reduce $\mathrm{P}$ lost with erosion soil.

Because of less P loss with erosion soil in 2001, we discussed the slope effect on $\mathrm{P}$ loss in erosion soil with the combined data of 2000 and 2001 (Table 6). It is obvious that $\mathrm{P}$ lost with erosion soil was through one or two rainfall events. From 10 to 30 degrees, P lost with erosion soil first increased, and then decreased. Twenty-five degrees was the turning point of slope. This result was just opposite to $\mathrm{P}$ loss in runoff. As $\mathrm{P}$ loss among 20, 25, and 30 degrees changed not much, this indicated there be a range of slope degree $\left(20 \sim 30^{\circ}\right)$ caused $\mathrm{P}$ lost with erosion soil increase.

Land use effects on P loss

Table 7 showed P losses of the six land uses and five slope treatments of FR in the study period. In agreement with the finding of other researchers (Thomas et al. 1992), most of phosphorus losses of FR, BR, and ICP occurred in erosion soil. But in SP, IS, and MS, P losses was primarily through runoff. When FR was fallowed in 2001, it produced much less P loss (Table 7). This result reflected the different routes of phosphorus loss in different land use systems. As the main components of landscape in the hilly area of loess plateau, if we could adjust the spatial structures of the six land use types in this study rationally, $\mathrm{P}$ loss in a landscape could decrease to acceptable level.

According to the above discussion, FR is the most common land use in loess plateau, and it also produced much more $\mathrm{P}$ loss in runoff and erosion soil than the other five land use types did. From 10 to 30 degrees, $\mathrm{P}$ losses first increased, and then decreased. Twenty-five degrees was the turning point

Table 7 P loss of different land uses in the study periods (2000-2001)

\begin{tabular}{|c|c|c|c|c|c|c|c|c|c|c|c|c|}
\hline Year & & SP & IS & FR & $\mathrm{BR}$ & ICP & MS & FR $10^{\circ}$ & FR $15^{\circ}$ & FR $20^{\circ}$ & FR $25^{\circ}$ & FR $30^{\circ}$ \\
\hline \multirow[t]{3}{*}{2000} & Runoff (mg) & 37.4 & 39.1 & 154.9 & 154.3 & 152.0 & 34.4 & 502.8 & 222.3 & 154.5 & 93.8 & 339.7 \\
\hline & Erosion soil (g) & 0 & 0 & 12,826 & 885 & 2,538 & 0 & 3,146 & 4,594 & 7,070 & 7,993 & 6,782 \\
\hline & Total $(\mathrm{g})$ & 0.04 & 0.04 & $12,826.2$ & 885.2 & 2538.2 & 0.03 & $3,146.50$ & $4,594.22$ & $7,070.15$ & $7,993.09$ & $6,782.34$ \\
\hline \multirow[t]{3}{*}{2001} & Runoff (mg) & 34.5 & 32.6 & 18.3 & 28.5 & 40.8 & 4.1 & 40.2 & 40.9 & 33.9 & 38.6 & 11.1 \\
\hline & Erosion soil (g) & 147 & 86 & 79 & 14 & 75 & 0 & 326 & 174 & 141 & 113 & 282 \\
\hline & Total (g) & 147.03 & 86.03 & 79.02 & 14.03 & 75.04 & 0.00 & 326.04 & 174.04 & 141.03 & 113.04 & 282.01 \\
\hline \multicolumn{2}{|c|}{ Total of 2000 and 2001} & 147.07 & 86.07 & $12,905.22$ & 899.23 & $2,613.24$ & 0.03 & $3,472.54$ & $4,768.26$ & $7,211.18$ & $8,106.13$ & $7,064.35$ \\
\hline
\end{tabular}

$S P$ seabuckthorn+poplar, IS immature seabuckthorn, FR Farmland, BR barrenland, ICP immature Chinese pine, $M S$ mature seabuckthorn. 
of slope value (Table 7). But the differences of P loss among 20, 25, and 30 degrees FR were not much. This result indicated that, in the hilly area of loess plateau, slope lands over 20 degrees should not be used as FR, and FR $\left(<15^{\circ}\right)$ would maintain high production level while simultaneously achieving environment quality.

\section{Conclusion}

In the same conditions, in FR, ICP, and BR, a considerably larger proportion of $\mathrm{P}$ loss occurred in the erosion soil, and this result was similar to other studies (Tang et al. 1987; Chen and Zhang 1990; Meng et al. 2001; Liu et al. 2001); in SP, IS, and MS, $\mathrm{P}$ losses was primarily through runoff, because SP, IS, and MS stopped erosion soil loss; FR produced much more P losses than SP, IS, ICP, BR, and MS because there were more erosion soil loss. For the slope treatment of FR, 20-30 degrees may be the slope ranges for $\mathrm{P}$ loss, and this was important for land use planning in this area.

SP, IS, and MS produced less runoff and soil loss than FR, BR, and ICP. They would decrease P loss through runoff and so have a positive impact on environment. FR $\left(<15^{\circ}\right)$ would maintain high production level while simultaneously achieve environment quality.

Although this study was operated for only 2 years, but the results was more believable. Extending the results to the hilly area of loess plateau, the sustainable land uses in the hilly area of loess plateau are SP, IS, MS, and FR $\left(<15^{\circ}\right)$.

Acknowledgements The authors thank An'sai Soil and Water Conservation Station, Institute of Soil and Water Conservation, Chinese Academy of Sciences for providing experimental plots and general assistance. This project was supported by the National Natural Science Foundation of China (Grant Nos.40501039 and 40621061).

\section{References}

Chambers, B., Garwood, T. W. G., \& Unwin, R. J. (2000). Controlling soil water erosion and phosphorus losses from arable land in England and Wales. Journal of Environmental Quality, 29, 145-150.

Chen, Y. Z., \& Luk, S. H. (1989). Sediment sources and recent changes in the sediment load of Yellow river, China. In S.
Rindwanich (Eds.), Land conservation for future generation. Proceedings of the 5th international soil erosion conference, Ministry of Agriculture. Bangkok, Thailand, 18-29 January 1998, (pp. 313-323). Bangkok: Department of Land Development.

Chen, L. D., Wang, J., Fu, B. J., \& Qiu, Y. (2001). Land use change in a small catchment of northern Loess Plateau, China. Agriculture, Ecosystems \& Environment, 86, 163172.

Chen, H., \& Zhang, S. (1990). Simulation of nitrogen and phosphorus loss in Loess Plateau. Geography Sciences (in Chinese), 11(2), 142-148.

FAO-UNESCO (1974). Soil map of the world (1:5,000,000). Food and agriculture organization of the United Nations. Paris: UNESCO.

Foy, R. H., Champ, W. S. T., \& Gibson, C. E. (1996). The effectiveness of restricting phosphorus loadings from sewage treatment works as a means of controlling eutrophication in Irish lakes. In P. S. Giller \& A. A. Myers (Eds.), Disturbance and recovery in ecological systems (pp. 136-154). Dublin, Ireland: Royal Irish Academy.

Fu, B. J., Chen, L. D., Ma, K. M., Zhou, H. F., \& Wang, J. (2000). The relationships between land use and soil conditions in the hilly area of the Loess Plateau in northern Shannxi, China. Catena, 39(1), 69-78.

Fu, B., \& Gulinck, H. (1994). Land evaluation in an area of severe erosion: The Loess Plateau of China. Land Degradation \& Rehabilitation, 5, 33-40.

Fu, B. J., Meng, Q. H., Qiu, Y., Zhao, W. W., Zhang, Q. J., \& Davidson, D. A. (2004). Effects of land use on soil erosion and nitrogen loss in the hilly area of the Loess Plateau, China. Land Degradation \& Development, 15, 87-96.

Fu, B. J., Zhang, Q. J., Chen, L. D., Zhao, W. W., Gulinck, H., Liu, G. B., et al. (2006). Temporal change in land use and its relationship to slope degree and soil type in a small catchment on the Loess Plateau of China. Catena, 65(1), 41-48.

Gilliam, J. W., Logan, T. J., \& Broadbent, F. E. (1985). Fertilizer use in relation to the environment. In O. P. Englestas (Ed.), Fertilizer technology and use (3rd ed., pp. 561-588). Madison, WI: SSSA.

Jia, H. Y., Peng, L., Peng, X. L., \& Yu, C. Z. (1994). Distribution and evaluation of soil nutrient resources in Loess Plateau. Journal of Soil and Water Conservation (in Chinese), 8(3), 22-28.

Jiang, D. (Ed.) (1997). Soil erosion and control models in Loess Plateau. Beijing: China Hydroelectricity Press (in Chinese).

Jones, O. R., \& Despain, W. (1995). Soil studies at Ansai. Journal of Soil and Water Conservation, 50, 336-339.

Kronvang, B., Ertebjerg, G., Grant, R., Kristensen, P., Hovmand, M., \& Kirkegaard, J. (1993). Nationwide monitoring of nutrients and their ecological effects: State of the Danish aquatic environment. Ambio, 22, 176-187.

Liu, C. S., Qi, S., \& Shi, M. C. (2001). Process of study on relationship between land use change and soil erosion. Journal of Soil and Water Conservation (in Chinese), 15 (5), 10-13.

Lu, Z. F., Zhang, W. J., Su, M., \& Li, G. X. (1988). Analysis and evaluation of some index for soil erosion. Journal of Soil and Water Conservation (in Chinese), 2(4), 60-65. 
Meng, Q. H., Fu, B. J., \& Yang, L. Z. H. (2001). Effects of land use on soil erosion and nutrients losses in the Three Gorges Reservoir Area, China. Soil Use and Management, 17, 288-291.

Myers, C. F., Meek, J., Tueller, S., \& Weinberg, A. (1985). Non-point sources of water pollution. Journal of Soil Water Conservation, 40, 14-18.

Nelson, W. C., \& Ehni, R. J. (1976). Land use and nonpoint pollution in the Sheyenne Valley. Water Resources Research, 1, 381-390.

Noy-Meir, I. (1973). Desert ecosystems: Environment and producers. Annual Review of Ecology and Systematics, 4, 25-51.

Peng, L. (1982). Contend of soil nitrogen and its improving methods in the loess area. Bulletin of Soil and Water Conservation (in Chinese), 4, 30-35.

Shaanxi Province Meteorology Bureau. (1992). Shaanxi Province climate data of land surface from 1951 to 1990. Xi'an: Shaanxi Province Meteorology Bureau (in Chinese).

Sharpley, A. N., Daniel, J. T., Sims, J. T., \& Pote, D. H. (1996). Determining environmentally sound soil phosphorus levels. Journal of Soil and Water Conservation, 51, 160-166.

Sharpley, A. N., Foy, B., \& Withers, P. (2000). Practical and innovative measures for the control of agricultural phosphorus losses to water: An overview. Journal of Environmental Quality, 29, 1-9.

Sharpley, A. N., Troeger, W. W., \& Smith, S. J. (1991). The measurement of bioavailable phosphorus in agriculture runoff. Journal of Environmental Quality, 20, 235-238.

Tang, K. L., \& Chen, Y. Z. (1991). Characterizes of soil erosion in Loess plateau and its treatment methods. Beijing: Chinese Science Technology Press (in Chinese).
Tang, K. L., Zhang, Z., Kong, X., Shi, R., \& Huang, Y. (1987). Study of soil erosion and soil degeneration in the Loess Plateau. Bulletin of Soil and Water Conservation (in Chinese), 7(6), 12-18.

Thomas, M. L., Lal, R., Logan, T., \& Fausey, N. R. (1992). Land use and management effects on nonpoint loading from Miamian soil. Soil Science Society of America Journal, 56, 1871-1875.

Trimble, S. W., \& Crosson, P. (2000). U.S. soil erosion rates Myth and reality. Science, 289, 248-250.

Uusi-Kamppa, J., Braskerud, B., Jansson, H., Syversen, N., \& Uusitalo, R. (2000). Buffer zones and constructed wetlands as filters for agricultural phosphorus. Journal of Environmental Quality, 29, 151-158.

Wang, B. Q., \& Liu, G. B. (1999). The effect of slope on soil nutrients loss. Journal of Soil and Water Conservation (in Chinese), 5(2), 18-22.

Wang, Q. J., Shen, J., \& Wang, W. Y. (1993). The laboratory experiment of solute in loess slope moving with surface runoff. Journal of Soil and Water Conservation (in Chinese), 7, 11-17.

Withers, P. J. A., Davidson, I. A., \& Foy, R. H. (2000). Prospects for controlling diffuse phosphorus loss to water. Journal of Environmental Quality, 29, 167-175.

Wu, Y., \& Yang, W. (Eds.) (1998). Forest and grassland vegetation constructions and its sustainable development in Loess Plateau. Beijing: Science Press (in Chinese).

Zhang, X. C., \& Lu, Z. F. (1996). Estimate of numerical value of crop soil and water conservation. Journal of Soil Erosion and Soil and Water Conservation (in Chinese), 7(2), 51-56.

Zhang, X. C., \& Shao, M. A. (2000). Influence of soil nitrogen loss on soil and environment under erosion conditions. Soil and Environment (in Chinese), 9(3), 249-252. 